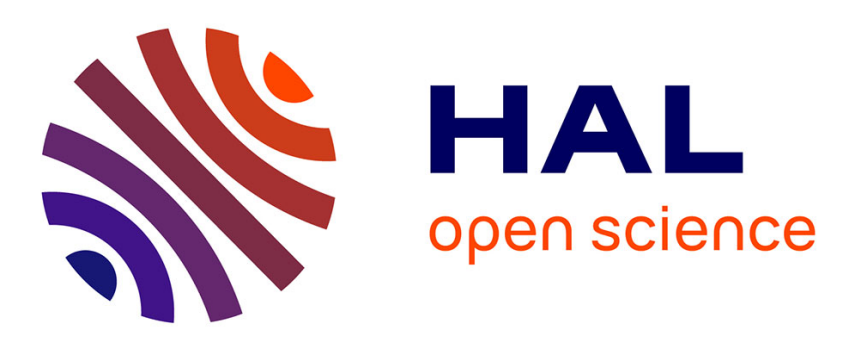

\title{
OSCILLATOR STRENGTHS FOR ALLOWED TRANSITIONS IN NEUTRAL OXYGEN : AN ASSESSMENT OF THE OPACITY PROJECT DATA ACCURACY
}

K. Butler, C. Zeippen

\section{To cite this version:}

K. Butler, C. Zeippen. OSCILLATOR STRENGTHS FOR ALLOWED TRANSITIONS IN NEUTRAL OXYGEN : AN ASSESSMENT OF THE OPACITY PROJECT DATA ACCURACY. Journal de Physique IV Proceedings, 1991, 01 (C1), pp.C1-141-C1-152. 10.1051/jp4:1991117 . jpa-00249755

\section{HAL Id: jpa-00249755 https://hal.science/jpa-00249755}

Submitted on 1 Jan 1991

HAL is a multi-disciplinary open access archive for the deposit and dissemination of scientific research documents, whether they are published or not. The documents may come from teaching and research institutions in France or abroad, or from public or private research centers.
L'archive ouverte pluridisciplinaire HAL, est destinée au dépôt et à la diffusion de documents scientifiques de niveau recherche, publiés ou non, émanant des établissements d'enseignement et de recherche français ou étrangers, des laboratoires publics ou privés. 
OSCILLATOR STRENGTHS FOR ALLOWED TRANSITIONS IN NEUTRAL OXYGEN : AN ASSESSMENT OF THE OPACITY PROJECT DATA ACCURACY

\author{
K. BUTLER and C.J. ZEIPPEN" \\ Institut für Astronomie und Astrophysik der Universität München, 1, \\ Scheinerstrasse, D-8000 München 80, Germany \\ * UPR 261 du CNRS et DAMAp, Observatoire de Paris, F-92190 Meudon, \\ France
}

\title{
Résumé.
}

Plusieurs séries de forces d'oscillateur pour des transitions permises dans l'oxygène neutre, calculées dans le cadre du projet international Opacity, sont présentées et comparées à des données tant expérimentales que théoriques obtenues par d'autres auteurs. On montre que les présents résultats sont d'une haute précision.

\section{Summary.}

Several series of oscillator strengths for allowed transitions in neutral oxygen, calculated in the framework of the international Opacity Project, are presented and compared with both experimental and theoretical data obtained by other authors. It is shown that the present results are of high accuracy.

\section{Introduction.}

The international Opacity Project (OP), mentioned in several other papers in this volume, aims at reestimating stellar envelope opacities (see the general description of the project by Seaton, 1987). In order to achieve this task, it is essential to calculate a large number of accurate radiative atomic data (term energies, oscillator strengths, photoionisation cross sections) and parameters for pressure broadening of spectral lines. Of course, the atomic data produced by the various participants to the $O P$ will also be of use in other fields of astrophysics. Needless to say, it is important to try to assess the accuracy of these new results.

The authors of the present report have already compared their cross sections for the photoionisation of the ${ }^{3} P^{e},{ }^{1} D^{e}$ and ${ }^{1} S^{e}$ states of neutral oxygen with recent theoretical and experimental work (see Butler \& Zeippen, 1990a, and references therein). The conclusion of this study is that the $O P$ cross sections are of very good accuracy and certainly precise enough for opacity calculations. The present paper will be concerned with several series of oscillator strengths for allowed transitions in the same atom. Our choice is justified by the fact that the neutral member of most isoelectronic sequences is among the most difficult, if not the most difficult one to treat accurately, and also by the possibility of comparing $O P$ data to other theoretical results and experimental measurements, thus complementing the assessment of Butler \& Zeippen (1990a). The bulk of the $O P$ radiative data for the oxygen isoelectronic sequence will be presented in a paper being prepared for the Atomic Data for Opacity Calculations (ADOC) series in J. Phys. B (Butler \& Zeippen, 1990b).

\section{Theoretical methods and physical models.}

The two most extended calculations to date have been performed independently by Bell \& Hibbert (1990, later referred to as $B H$ ) and by the authors of this paper (later referred to as $B Z$ ), using the close-coupling approximation (Burke \& Seaton, 1971) as implemented in a revised version of the RMATRX program described by Berrington et al. $(1974,1978)$ and new codes based on optimised techniques (see, for example, Seaton, 1985) for the asymptotic region. The new OPACITY set of computer programs is described by Berrington $e t$ 
al. (1987). Let us recall that, in the collisional formalism adopted by $B H$ and $B Z$, the total system (here neutral oxygen) is considered as being formed of a target or residual ion (here $O^{+}$) plus a scattered electron. The wavefunctions describing the target are of course an essential element of the calculation. This is where the main difference between the $B H$ and $B Z$ calculations lies.

$B Z$ chose to base their work on the target wavefunctions described by Butler \& Zeippen (1990a): only the eight $O^{+}$terms corresponding to the ground complex (configurations $2 p^{3}, 2 s 2 p^{4}, 2 p^{5}$ ) are considered and the orbitals are built with the help of a version of the code SUPERSTRUCTURE (Eissner et al., 1974) due to Nussbaumer \& Storey (1978). On the other hand, $B H$ decided to use the wavefunctions built by Bell et al. (1989) : eleven $O^{+}$terms are included (thus incorporating some $n=3$ terms) and the orbitals are produced by the codes CIV3 (Hibbert, 1975) and CIVPOL (Le Dourneuf, 1990). A complete discussion of the target problem can be found in Butler \& Zeippen (1990a) who show that their eight-term target is adequate for photoionisation calculations. A comparison between the findings of $B H$ and $B Z$ concerning oscillator strengths will provide a further test of the importance of the $n=3$ target terms.

The most complete previous elaborate calculations are by Pradhan \& Saraph (1977, later referred to as $P S$ ) who also used the close-coupling approximation, but as implemented in the University College London (UCL) chain of computer programs (Eissner, 1972; Crees et al., 1978; Saraph, 1976), and with a seven-term $O^{+}$ target constructed by Pradhan (1976) with the help of SUPERSTRUCTURE (Eissner et al., 1974). Other published theoretical values were obtained by Zeippen et al. (1977), using SUPERSTRUCTURE, by Ganas (1980), using an analytic atomic independent-particle model potential, and by Froese Fischer (1987), using the multi-configuration Hartree-Fock method with Breit-Pauli relativistic corrections $(M C H F+B P)$.

Finally, it should be noted that $B H$ used the CIV3 code (Hibbert, 1975) to perform configuration-interaction $(C I)$ calculations of oscillator strengths for a few of the transitions they treated collisionally. The corresponding results are listed in the present tables with a $\mathrm{BH} 2$ label, while the values they obtained with the OPACITY package are marked $B H 1$.

\section{Comparison between the various sets of results.}

$B H$ discuss in some detail their oscillator strengths as compared to previous work. They mention the existence of the $O P$ data but note that those are as yet unpublished. In the present report, we will complete the tables given in $B H$ by adding our $O P$ results and extending the comparison. $B H$ list the values they obtained both with the length $(L)$ and velocity $(V)$ formalisms. Considering the fact that the $L$ data are generally rated as the most accurate, and also that only the $L$ oscillator strengths are used in subsequent $O P$ opacity calculations or indeed calculated for all transitions, we will not reproduce any $V$ results here. However, since the agreement between the $L$ and $V$ data is an indication of the quality of a given calculation, mention will be made in the text of this aspect for some transitions.

\section{a. The ${ }^{3} P-{ }^{3} S^{\circ}$ transitions (see Table 1).}

The discrepancy between the $B H 1$ and $B Z$ sets of data is never more than $3 \%$ for all transitions, except for the transitions $2 p^{4}-2 p^{3} n s$, with $n=4$ to 10 , for which the difference goes up to $12 \%$. In these cases, the $O P$ values of $B Z$ are closer to the findings of $P S$ and Zeippen et al. (1977). Also, $B Z$ agree better with the recent experimental result of Doering et $a l$. (1985) and they tend to be in better accord with Ganas (1980). On the other hand, for the $2 p^{4}-2 p^{3} n s$ transitions, $B H 1$ obtain a better agreement between their $L$ and $V$ data than $B Z$ (typically, a maximum discrepancy of $10 \%$, as compared to $20 \%$ ). Finally, the $B H 2$ findings are closer to the $B Z$ or $P S$ results than the $B H 1$ ones. The conclusion must be that the $O P$ data calculated by $B Z$ are accurate to $10 \%$ or better (much better for most transitions in the table).

\section{b. The ${ }^{3} S^{o}-{ }^{3} P$ transitions (see Table 2).}

The discrepancy between the $B H 1$ and $B Z$ sets of data is within $5 \%$ for most transitions, and within $10 \%$ for the transitions $4 s-5 p, 6 p ; 5 s-7 p, 8 p ; 6 s-8 p, 9 p, 10 p ; 7 s-9 p, 10 p$. It goes up to $14 \%$ for the transitions $3 s-4 p ; 5 s-9 p, 10 p$. As pointed out by $B H$, it is of course difficult to obtain accurate values for very small oscillator strengths. It should be noted, however, that the agreement between the $O P L$ and $V$ results by $B Z$, for the $3 s-n p$ and $4 s-n p$ transitions (and in particular for the transition $3 s-4 p$ ), is markedly better 
than the one obtained by $B H 1$ (typically, a maximum discrepancy of a few percent, as compared to up to a factor of four). In conclusion, the $O P$ set of data by $B Z$ will be rated as accurate to $10 \%$ (and better for most transitions in the table).

\section{c. The ${ }^{3} P-{ }^{3} D^{\circ}$ transitions (see Table 8 ).}

The discrepancy between the $B H 1$ and $B Z$ sets of data is within $5 \%$ for most transitions and within $10 \%$ for the others, with the remarkable exception of the $2 p^{4}-2 p^{3} 4 d$ transition for which the discrepancy goes up to a factor of two! Note that for this latter transition, the $B Z$ result is much closer to the theoretical values of $B H 2, P S$ and Ganas (1980), as well as to the experimental finding of Doering $e t$ al. (1985). Also, where available, the $V$ data calculated by $B Z$ agree better with the corresponding $L$ results than is the case for the $B H 1$ values (typically, a maximum discrepancy of $11 \%$, as compared to $22 \%$ ). Finally, $\mathrm{BZ}$ are closer to Doering et $a l$. (1985) for the $2 p^{4}-2 p^{3} 3 d$ transition, closer to $P S$ for the $2 p^{4}-2 p^{3} 5 d$ and $3 p-4 d$ transitions, and closer to Wiese et al. (1966) for the $3 p-4 d$ transition than $B H 1$. The $O P$ data of $B Z$ can then be considered as accurate to within $10 \%$ (and better for most transitions in the table).

\section{d. The ${ }^{3} D^{o}-{ }^{3} P$ transitions (see Table 4).}

The discrepancy between the $B H 1$ and $B Z$ sets of data is not more than $5 \%$ for the $3 d-n p ; n d-(n+1) p$ transitions, and not more than $10 \%$ for the others, with the exception of the $4 d-8 p, 9 p, 10 p$ transitions, for which it goes up to $17 \%$. It should be noted that the latter oscillator strengths are very small and that the agreement between the $L$ and $V$ results of $B H 1$ gets worse as $n$ increases in the $4 d-n p$ series of transitions. The $O P$ results of $B Z$ will be rated as accurate to $10 \%$ or better for all significant transitions.

\section{e. The ${ }^{5} D^{\circ}-{ }^{5} P$ transitions (see Table 5).}

The discrepancy between the $B H 1$ and $B Z$ sets of data is not more than $5 \%$ for the $n d-(n+1) p$ transitions, but goes up to about a factor of two for the $n d-(n+2) p$ transitions. The oscillator strengths are much smaller (and therefore more difficult to get right) for the latter transitions. The agreement between the $L$ and $V$ results of $B H 1$ is less good for the $n d-(n+2) p$ cases and also markedly worse than the agreement obtained by $B Z$ for the $3 d-5 p$ case (a discrepancy of $55 \%$, as compared to $7 \%$ ). The $O P$ data by $B Z$ should be accurate to within $5 \%$ for the $n d-(n+1) p$ transitions but no solid conclusion can be drawn for the $n d-(n+2) p$ transitions.

\section{f. The ${ }^{5} S^{o}-{ }^{5} P$ transitions (see Table 6).}

The discrepancy between the $B H 1$ and $B Z$ sets of data is within $5 \%$ for all $n s-n p$ transitions for $n s-(n+1) p$ transitions, with $n=4$ to 9 , and for $n s-(n+2) p$ transitions, with $n=7$ and 8 , and not more than $10 \%$ for the others, with the exception of the $4 s-(7$ to 10)p and the $5 s-10 p$ transitions, for which it goes up to $26 \%$. The latter transitions correspond to small oscillator strengths and the agreement between $L$ and $V$ results obtained by $B Z$ is better than the one achieved by $B H$ (typically, a maximum discrepancy of $12 \%$, as compared to $45 \%$ ). In conclusion, the $O P$ data of $B Z$ will rated as accurate to within $10 \%$ for all significant transitions.

\section{g. The ${ }^{5} P-{ }^{5} S^{\circ}$ transitions (see Table 7).}

The discrepancy between the $B H 1$ and $B Z$ sets of data is not more than $3 \%$ for all transitions. The accuracy of the $O P$ data can thus be rated as to within a few percent.

\section{h. The ${ }^{5} P-{ }^{5} D^{\circ}$ transitions (see Table 8).}

The discrepancy between the $B H 1$ and $B Z$ sets of data is not more than $5 \%$ for all transitions, except for the $3 p-(6$ to 10)d transitions for which it goes up to $7 \%$. Note that for all the latter cases the agreement between $L$ and $V$ results is better in $B Z$ than in $B H 1$ (typically, a maximum discrepancy of $5 \%$, as compared to $16 \%$ ). Here again, the $O P$ data of $B Z$ can be rated as accurate to better than $10 \%$. 


\section{Conclusion.}

From the detailed comparison above, it appears that both the $B H 1$ and $B Z$ sets of data are very accurate, with perhaps a few dubious values in the first set. This might be due to the fact that the target used by $B Z$ is a well-balanced description of the ground complex $O^{+}$, while by incorporating only some of the $n=3$ terms in their calculation, $B H$ do not obtain a completely coherent model. Their study is useful, however, in showing that the effect of those excited terms is not essential as compared to that of the $n=2$ terms. To assess completely the importance of the target terms outside the complex, even larger calculations are needed but they would demand large amounts of computer time and human effort, and could require changes in the numerical methods or theoretical formalisms. As it is, confronted by the necessity of performing accurate but manageable calculations for the whole isoelectronic sequence, $B Z$ seem to have produced data, which, from the first two tests of their accuracy (Butler \& Zeippen, 1990a, and present paper) appear to be more than precise enough (well within the $10 \%$ range for all significant transitions) for opacity calculations and perhaps other astrophysical problems as well. It should also be pointed out that the older calculations by $P S$ and Zeippen et al. (1977) gave results whose accuracy is quite satisfactory, considering the computing facilities available at the time. On the experimental front, as already noted by $B H$, the measurements are scattered, illustrating the difficulty of obtaining accurate results in this case. Some of the experimental data come, however, close to calculated values, as mentioned in the text or shown in the tables.

\section{Acknowledgements.}

The $B Z$ calculations were performed on the NAS, IBM and VP computers at the CIRCE (Orsay, France), on the CRAY computers at the CCVR (Ecole Polytechnique, Palaiseau, France) and on the CDC computers at the Leibniz Rechenzentrum (München, Germany). The CPU time used on the CRAY machines was allocated by the Conseil Scientifique du Centre de Calcul Vectoriel pour la Recherche, while part of the CPU time used on the VP machine was allocated by the CNRS. Part of the $B Z$ work was done during visits by $\mathrm{KB}$ to Meudon and CJZ to Munich over the 1985-1990 period. The visits were funded by the Observatoire de paris, the CNRS DRCI and the DFG. The hospitality of the Observatoire de Paris and of the Universitätssternwarte München is gratefully acknowledged. The authors thank Drs. K.L. Bell and A. Hibbert for a preprint of their work. KB received support from the DFG under Grant Ku 474/13-2.

\section{References.}

Bell, K.L., Burke, P.G., Hibbert, A., Kingston, A.E. (1989) J. Phys. B 22, 3197.

Bell, K.L., Hibbert, A. (1990) J. Phys. B 23, $2673(B H)$.

Berrington, K.A., Burke, P.G., Butler, K., Seaton, M.J., Storey, P.J., Taylor, K.T., Yu, Y. (1987) J. Phys. B 20, 6379 .

Berrington, K.A., Burke, P.G., Chang, J.J., Chivers, A.T., Robb, W.D., Taylor, K.T. (1974) Comput. Phys. Commun. 8, 149.

Berrington, K.A., Burke, P.G., Le Dourneuf, M., Robb, W.D., Taylor, K.T., Vo Ky, L. (1978) Comput. Phys. Commun. 14, 367.

Bischel, W.K., Perry, B.E., Crosely, D.R. (1981) Chem. Phys. Lett. 82, 85.

Bromander, J., Duric, N., Erman, P., Larsson, M. (1978) Phys. Scr. 17, 119.

Burke, P.G., Seaton, M.J. (1971) Meth. Comput. Phys. 10, 1.

Butler, K., Zeippen, C.J. (1990a) Astron. Astrophys. 234, 569.

Butler, K., Zeippen, C.J. (1990b) J. Phys. B in preparation.

Clyne, M.A.A., Piper, L.G. (1976) J. Chem. Soc. Faraday Trans. II 72, 2178.

Crees, M.A., Seaton, M.J., Wilson, P.M.H. (1978) Comput. Phys. Commun. 15, 23.

Doering, J.P., Gulcicek, E.E., Vaughan, S.O. (1985) J. Geophys. Res. 90, 5279.

Eissner, W. (1972) in The Physics of Electronic and Atomic Collisions (Ed. T.R. Govers \& F.J. de Heer)

North Holland (Amsterdam) p.460.

Eissner, W., Jones, M., Nussbaumer, H. (1974) Comput. Phys. Commun. 8, 270.

Froese Fischer, C. (1987) J. Phys. B 20, 1193.

Ganas, P.S. (1980) Mol. Phys. 39, 1513.

Hibbert, A. (1975) Comput. Phys. Commun. 9, 141.

Jenkins, D.B. (1985) J. Quant. Spectrosc. Radiat. Transfer 34, 55. 
Kernahan, J.A., Simpson, F.R. (1982) Nucl. Instrum. Methods 202, 49.

Kroll, S., Lundberg, H., Persson, A., Svanberg, S. (1985) Phys. Rev. Lett. 55, 284.

Le Dourneuf, M. (1990) Comput. Phys. Commun. to be submitted.

Lin, C.C., Irwin, D.J.G., Kernahan, J.A., Livingston, A.E., Pinnington, E.H. (1972) Can. J. Phys. 50, 2496.

Nussbaumer, H., Storey, P.J. (1978) Astron. Astrophys. 64, 139.

Pradhan, A.K. (1976) J. Phys. B 9, 433.

Pradhan, A.K., Saraph, H.E. (1977) J. Phys. B 10, 3365 (PS).

Reader, J., Corliss, C.H., Wiese, W.L., Martin, G.A. (1980) Atomic Transition Probabilities NSRDS-NBS

68 (Washington DC : US Govt. Printing Office).

Saraph, H.E. (1976) J. Phys. B 9, 2379.

Seaton, M.J. (1985) J. Phys. B 18, 2111.

Seaton, M.J. (1987) J. Phys. B 20, 6363.

Smith, W.H., Bromander, J., Curtis, L.J., Berry, H.G., Buchta, R. (1971) Astrophys. J. 165, 217.

Wiese, W.L., Smith, M.W., Glennon, B.M. (1966) Atomic Transition Probabilities NSR.DS-NBS 4 (Washington DC : US Govt. Printing Office).

Zeippen, C.J., Seaton, M.J., Morton, D.C. (1977) Mon. Not. R. Astr. Soc. 181, 527. 


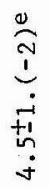
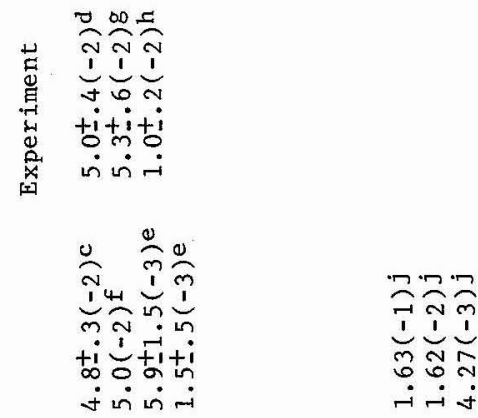

党

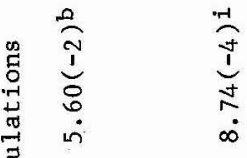

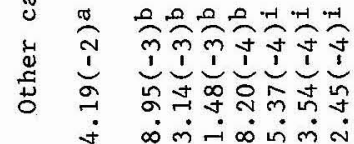

芩

\begin{tabular}{|c|c|c|c|}
\hline$\frac{5}{4}$ & \multicolumn{2}{|c|}{ 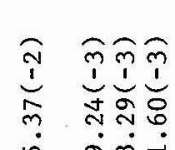 } & 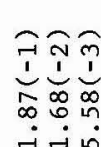 \\
\hline
\end{tabular}

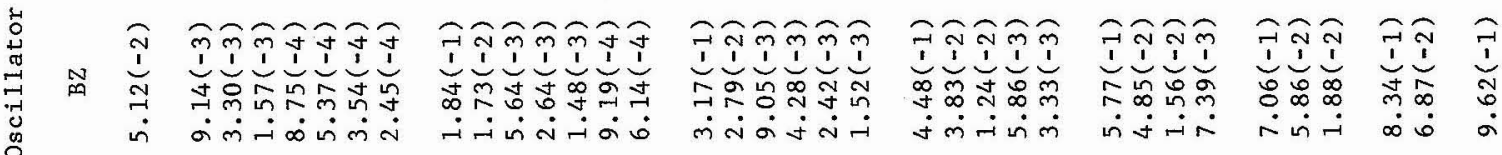

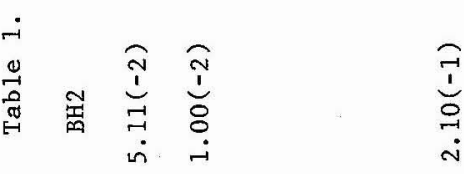

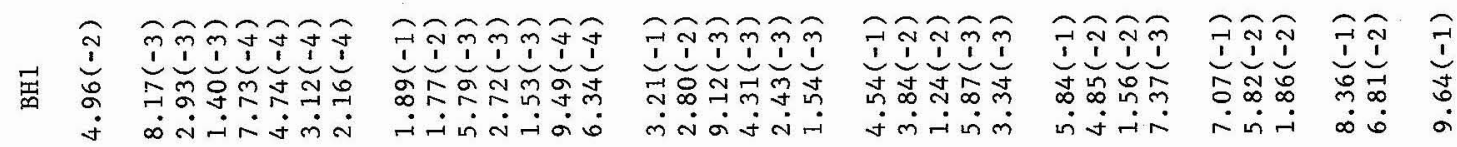

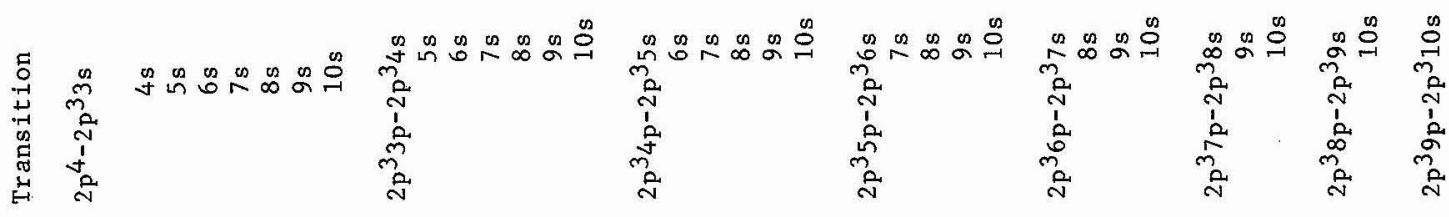



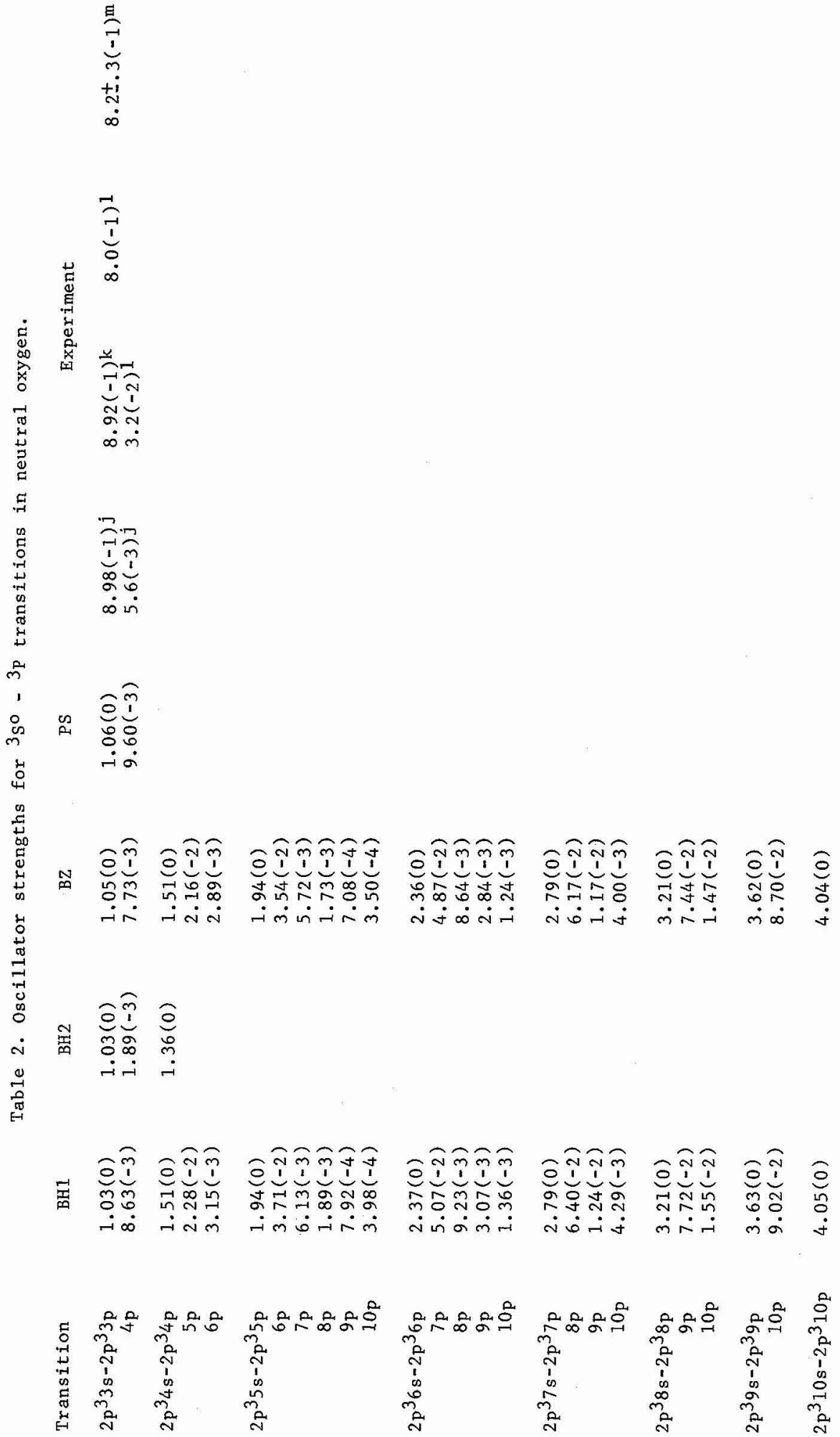


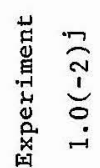

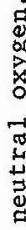

章

鬲

1

लि

in

岕

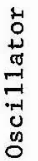

in

$\underset{\substack{0 \\-1}}{0}$

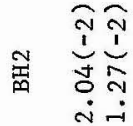

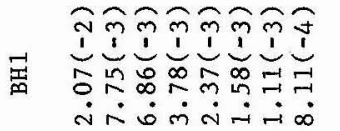

$\stackrel{\substack{n \\ 1}}{\stackrel{n}{n}}$

कิ
1
0
$+i$
-1
0

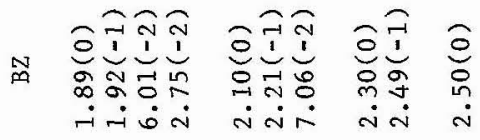

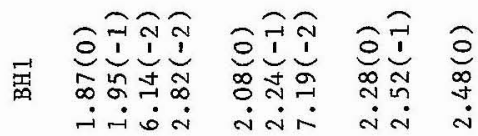

$+\stackrel{i}{+}+$

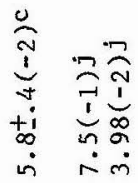

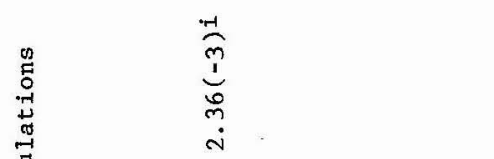

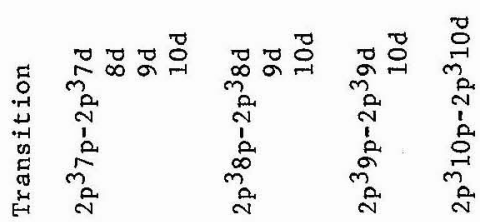

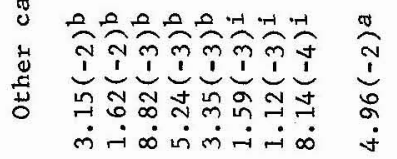

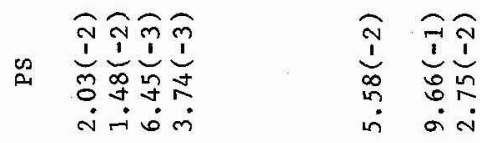

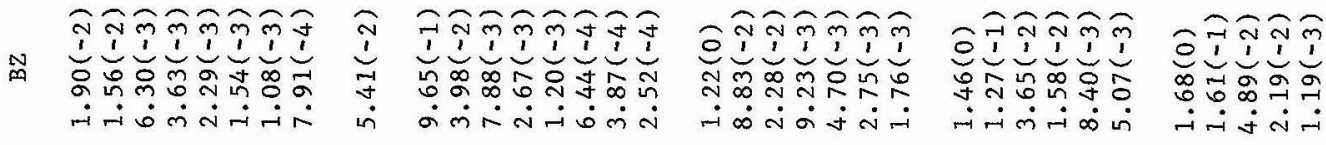

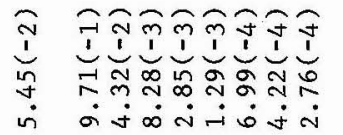

केत्रुले लि

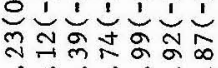

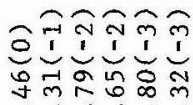

ฮิํำ

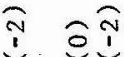

m $8 \stackrel{1}{\circ}$

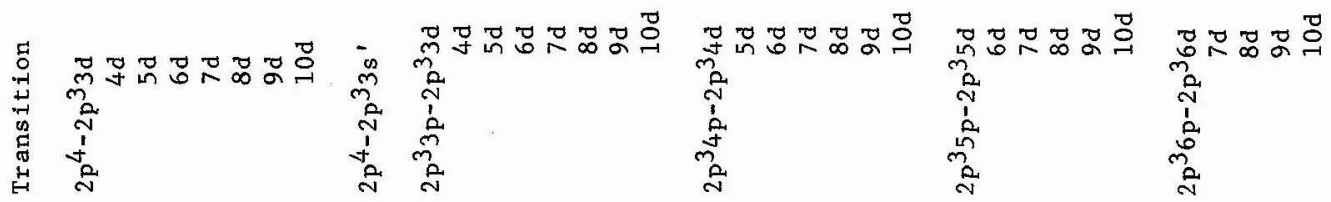


Table 4. Oscillator strengths for $3 D^{O}-3 p$ transitions in neutral oxygen.

\begin{tabular}{|c|c|c|c|}
\hline Transition & BH 1 & BH2 & $B Z$ \\
\hline $\begin{array}{r}2 \mathrm{p}^{3} 3 \mathrm{~d}-2 \mathrm{p}^{3} 4 \mathrm{p} \\
5 \mathrm{p} \\
6 \mathrm{p} \\
7 \mathrm{p} \\
8 \mathrm{p} \\
9 \mathrm{p} \\
10 \mathrm{p}\end{array}$ & $\begin{array}{l}1.85(-1) \\
3.79(-3) \\
1.02(-3) \\
4.40(-4) \\
2.37(-4) \\
1.44(-4) \\
9.47(-5)\end{array}$ & $1.81(-1)$ & $\begin{array}{l}1.82(-1) \\
4.00(-3) \\
1.07(-3) \\
4.61(-4) \\
2.46(-4) \\
1.49(-4) \\
9.76(-5)\end{array}$ \\
\hline $\begin{array}{r}2 p^{3} 4 d-2 p^{3} 5 p \\
6 p \\
7 p \\
8 p \\
9 p \\
10 p\end{array}$ & $\begin{array}{l}3.54(-1) \\
6.30(-3) \\
1.63(-3) \\
7.07(-4) \\
3.82(-4) \\
2.34(-4)\end{array}$ & & $\begin{array}{l}3.53(-1) \\
6.70(-3) \\
1.82(-3) \\
8.17(-4) \\
4.53(-4) \\
2.83(-4)\end{array}$ \\
\hline $\begin{array}{r}2 \mathrm{p}^{3} 5 \mathrm{~d}-2 \mathrm{p}^{3} 6 \mathrm{p} \\
7 \mathrm{p} \\
8 \mathrm{p} \\
9 \mathrm{p} \\
10 \mathrm{p}\end{array}$ & $\begin{array}{l}5.23(-1) \\
7.81(-3) \\
2.02(-3) \\
8.89(-4) \\
4.91(-4)\end{array}$ & & $\begin{array}{l}5.22(-1) \\
8.49(-3) \\
2.20(-3) \\
9.47(-4) \\
5.33(-4)\end{array}$ \\
\hline $\begin{array}{r}2 \mathrm{p}^{3} 6 \mathrm{~d}-2 \mathrm{p}^{3} 7 \mathrm{p} \\
8 \mathrm{p} \\
9 \mathrm{p} \\
10 \mathrm{p}\end{array}$ & $\begin{array}{l}6.78(-1) \\
8.85(-3) \\
2.20(-3) \\
9.63(-4)\end{array}$ & & $\begin{array}{l}6.83(-1) \\
9.68(-3) \\
2.42(-3) \\
1.06(-3)\end{array}$ \\
\hline $\begin{array}{r}2 p^{3} 7 d-2 p^{3} 8 p \\
9 p \\
10 p\end{array}$ & $\begin{array}{l}8.33(-1) \\
9.56(-3) \\
2.29(-3)\end{array}$ & & $\begin{array}{l}8.41(-1) \\
1.05(-2) \\
2.55(-3)\end{array}$ \\
\hline $\begin{array}{r}2 p^{3} 8 d-2 p^{3} 9 p \\
10 p\end{array}$ & $\begin{array}{l}9.87(-1) \\
1.01(-2)\end{array}$ & & $\begin{array}{l}9.96(-1) \\
1.12(-2)\end{array}$ \\
\hline $2 p^{3} 9 d-2 p^{3} 10 p$ & $1.14(0)$ & & $1.15(0)$ \\
\hline
\end{tabular}

Table 5. Oscillator strengths for $5 D^{O}-5 p$ transitions in neutral oxygen.

$\begin{array}{rcccc}\text { Transition } & \text { BH } 1 & \text { BH2 } & \text { BZ } & \text { PS } \\ 2 \mathrm{p}^{3} 3 \mathrm{~d}-2 \mathrm{p}^{3} 4 \mathrm{p} & 1.61(-1) & 1.59(-1) & 1.59(-1) & 1.59(-1) \\ 5 \mathrm{p} & 7.77(-4) & & 9.34(-4) & \\ 2 \mathrm{p}^{3} 4 \mathrm{~d}-2 \mathrm{p}^{3} 5 \mathrm{p} & 3.18(-1) & & 3.14(-1) & \\ 6 \mathrm{p} & 1.10(-3) & & 1.41(-3) & \\ 2 \mathrm{p}^{3} 5 \mathrm{~d}-2 \mathrm{p}^{3} 6 \mathrm{p} & 4.66(-1) & & 4.62(-1) & \\ 7 \mathrm{p} & 1.10(-3) & & 1.54(-3) & \\ 2 \mathrm{p}^{3} 6 \mathrm{~d}-2 \mathrm{p}^{3} 7 \mathrm{p} & 5.95(-1) & & 6.06(-1) & \\ 8 \mathrm{p} & 9.72(-4) & & 1.48(-3) & \\ 2 \mathrm{p}^{3} 7 \mathrm{~d}-2 \mathrm{p}^{3} 8 \mathrm{p} & 7.32(-1) & & 7.47(-1) \\ 9 \mathrm{p} & 7.96(-4) & & 1.35(-3) & \\ 2 \mathrm{p}^{3} 8 \mathrm{~d}-2 \mathrm{p}^{3} 9 \mathrm{p} & 8.67(-1) & & 8.86(-1) & \\ 10 \mathrm{p} & 6.17(-4) & & 1.18(-3) & \\ 2 \mathrm{p}^{3} 9 \mathrm{~d}-2 \mathrm{p}^{3} 10 \mathrm{p} & 1.00(0) & & 1.02(0) & \end{array}$


Table 6. Oscillator strengths for ${ }^{5} \mathrm{~S}^{\circ}-{ }^{5} \mathrm{P}$ transitions in neutral oxygen.

\begin{tabular}{|c|c|c|c|c|c|c|}
\hline \multirow{2}{*}{$\begin{array}{l}\text { Transition } \\
2 \mathrm{p}^{3} 3 \mathrm{~s}-2 \mathrm{p}^{3} 3 \mathrm{p}\end{array}$} & \multirow{2}{*}{$\begin{array}{c}\text { BHI } \\
9.76(-1) \\
2.87(-3)\end{array}$} & \multirow{2}{*}{$\begin{array}{c}\text { BH2 } \\
9.71(-1) \\
7.85(-3)\end{array}$} & \multirow{2}{*}{$\begin{array}{c}B Z \\
9.78(-1) \\
3.19(-3)\end{array}$} & \multirow{2}{*}{$\begin{array}{c}\text { PS } \\
9.78(-1) \\
3.27(-3)\end{array}$} & \multicolumn{2}{|c|}{ Experiment } \\
\hline & & & & & $\begin{array}{l}9.22(-1) \mathbf{j} \\
2.29(-3) \mathbf{j}\end{array}$ & $\begin{array}{l}7.0(-1)^{1} \\
2.9(-3)^{1}\end{array}$ \\
\hline $\begin{array}{r}2 \mathrm{p}^{3} 4 \mathrm{~s}-2 \mathrm{p}^{3} 4 \mathrm{p} \\
5 \mathrm{p} \\
6 \mathrm{p} \\
7 \mathrm{p} \\
8 \mathrm{p} \\
9 \mathrm{p} \\
10 \mathrm{p}\end{array}$ & $\begin{array}{l}1.48(0) \\
1.50(-2) \\
1.72(-3) \\
4.00(-4) \\
1.35(-4) \\
5.72(-5) \\
2.82(-5)\end{array}$ & $1.53(0)$ & $\begin{array}{l}1.46(0) \\
1.56(-2) \\
1.89(-3) \\
4.67(-4) \\
1.66(-4) \\
7.37(-5) \\
3.80(-5)\end{array}$ & $1.46(0)$ & & \\
\hline $\begin{array}{r}2 \mathrm{p}^{3} 5 \mathrm{~s}-2 \mathrm{p}^{3} 5 \mathrm{p} \\
6 \mathrm{p} \\
7 \mathrm{p} \\
8 \mathrm{p} \\
9 \mathrm{p} \\
10 \mathrm{p}\end{array}$ & $\begin{array}{l}1.92(0) \\
2.85(-2) \\
4.30(-3) \\
1.28(-3) \\
5.26(-4) \\
2.63(-4)\end{array}$ & & $\begin{array}{l}1.90(0) \\
2.93(-2) \\
4.60(-3) \\
1.39(-3) \\
5.84(-4) \\
2.97(-4)\end{array}$ & & & \\
\hline $\begin{array}{r}2 \mathrm{p}^{3} 6 \mathrm{~s}-2 \mathrm{p}^{3} 6 \mathrm{p} \\
7 \mathrm{p} \\
8 \mathrm{p} \\
9 \mathrm{p} \\
10 \mathrm{p}\end{array}$ & $\begin{array}{l}2.35(0) \\
4.15(-2) \\
7.18(-3) \\
2.33(-3) \\
1.03(-3)\end{array}$ & & $\begin{array}{l}2.33(0) \\
4.31(-2) \\
7.61(-3) \\
2.51(-3) \\
1.12(-3)\end{array}$ & & & \\
\hline $\begin{array}{r}2 p^{3} 7 s-2 p^{3} 7 p \\
8 p \\
9 p \\
10 p\end{array}$ & $\begin{array}{l}2.75(0) \\
5.48(-2) \\
1.02(-2) \\
3.47(-3)\end{array}$ & & $\begin{array}{l}2.75(0) \\
5.68(-2) \\
1.07(-2) \\
3.70(-3)\end{array}$ & & & \\
\hline $\begin{array}{r}2 \mathrm{p}^{3} 8 \mathrm{~s}-2 \mathrm{p}^{3} 8 \mathrm{p} \\
9 \mathrm{p} \\
10 \mathrm{p}\end{array}$ & $\begin{array}{l}3.17(0) \\
6.79(-2) \\
1.32(-2)\end{array}$ & & $\begin{array}{l}3.17(0) \\
7.03(-2) \\
1.38(-2)\end{array}$ & & & \\
\hline $\begin{array}{r}2 p^{3} 9 s-2 p^{3} 9 p \\
10 p\end{array}$ & $\begin{array}{l}3.59(0) \\
8.08(-2)\end{array}$ & & $\begin{array}{l}3.59(0) \\
8.36(-2)\end{array}$ & & & \\
\hline $2 p^{3} 10 s-2 p^{3} 10 p$ & $4.00(0)$ & & $4.01(0)$ & & & \\
\hline
\end{tabular}

Table 7. Oscillator strengths for ${ }^{5} \mathrm{P}-{ }^{5} \mathrm{~S}^{\circ}$ transitions in neutral oxygen.

$\begin{array}{rccccc}\text { Transition } & \text { BH } 1 & \text { BH2 } & \text { BZ } & \text { PS } & \text { Experiment } \\ 2 \mathrm{p}^{3} 3 \mathrm{p}-2 \mathrm{p}^{3} 4 \mathrm{~s} & 1.65(-1) & 1.70(-1) & 1.64(-1) & 1.64(-1) & 1.73(-1) \mathrm{j} \\ 5 \mathrm{~s} & 1.73(-2) & & 1.69(-2) & 1.68(-2) & 1.48(-2) \mathrm{j} \\ 6 \mathrm{~s} & 5.78(-3) & & 5.61(-3) & 8.66(-3) & 4.50(-3) \mathrm{j} \\ 7 \mathrm{~s} & 2.73(-3) & & 2.65(-3) & & \\ 8 \mathrm{~s} & 1.53(-3) & & 1.48(-3) & \\ 9 \mathrm{~s} & 9.49(-4) & & 9.23(-3) & \\ 10 \mathrm{~s} & 6.34(-4) & & 6.17(-4) & & \\ 2 \mathrm{p}^{3} 4 \mathrm{p}-2 \mathrm{p}^{3} 5 \mathrm{~s} & 2.97(-1) & & & \\ 6 \mathrm{~s} & 2.82(-2) & & 2.96(-1) & 3.00(-1) & \\ 7 \mathrm{~s} & 9.34(-3) & & 2.80(-2) & 2.16(-2) & \\ 8 \mathrm{~s} & 4.44(-3) & 9.22(-3) & & \\ 9 \mathrm{~s} & 2.51(-3) & & 4.38(-3) & & \\ 10 \mathrm{~s} & 1.58(-3) & & 2.48(-3) & & \end{array}$


Table 7. Continued.

$\begin{array}{rcc}\text { Transition } & \text { BH } 1 & B Z \\ 2 \mathrm{p}^{3} 5 \mathrm{p}-2 \mathrm{p}^{3} 6 \mathrm{~s} & 4.27(-1) & 4.29(-1) \\ 7 \mathrm{~s} & 3.89(-2) & 3.86(-2) \\ 8 \mathrm{~s} & 1.27(-2) & 1.26(-2) \\ 9 \mathrm{~s} & 6.05(-3) & 6.00(-3) \\ 10 \mathrm{~s} & 3.45(-3) & 3.42(-3) \\ & & \\ 2 \mathrm{p}^{3} 6 \mathrm{p}-2 \mathrm{p}^{3} 7 \mathrm{~s} & 5.56(-1) & 5.60(-1) \\ 8 \mathrm{~s} & 4.92(-2) & 4.89(-2) \\ 9 \mathrm{~s} & 1.60(-2) & 1.59(-2) \\ 10 \mathrm{~s} & 7.60(-3) & 7.54(-3) \\ & 6.86(-1) & 6.90(-1) \\ 2 \mathrm{p}^{3} 7 \mathrm{p}-2 \mathrm{p}^{3} 8 \mathrm{~s} & 5.93(-2) & 5.90(-2) \\ 9 \mathrm{~s} & 1.91(-2) & 1.90(-2) \\ 10 \mathrm{~s} & 8.15(-1) & 8.19(-1) \\ 2 \mathrm{p}^{3} 8 \mathrm{p}-2 \mathrm{p}^{3} 9 \mathrm{~s} & 6.93(-2) & 6.89(-2) \\ 10 \mathrm{~s} & 9.44(-1) & 9.49(-1) \\ 2 \mathrm{p}^{3} 9 \mathrm{p}-2 \mathrm{p}^{3} 10 \mathrm{~s} & & \end{array}$

Table 8. Oscillator strengths for $5 p-5 D^{\circ}$ transitions in neutral oxygen.

\begin{tabular}{|c|c|c|c|c|c|c|}
\hline Transition & BH1 & BH2 & $\mathrm{BZ}$ & PS & Exper & ent \\
\hline $\begin{array}{r}2 p^{3} 3 p-2 p^{3} 3 d \\
4 d \\
5 d \\
6 d \\
7 d \\
8 d \\
9 d \\
10 d\end{array}$ & $\begin{array}{l}9.28(-1) \\
7.50(-2) \\
1.99(-2) \\
8.16(-3) \\
4.19(-3) \\
2.46(-3) \\
1.57(-3) \\
1.07(-3)\end{array}$ & $\begin{array}{l}9.50(-1) \\
8.03(-2)\end{array}$ & $\begin{array}{l}9.26(-1) \\
7.23(-2) \\
1.89(-2) \\
7.67(-3) \\
3.91(-3) \\
2.29(-3) \\
1.47(-3) \\
1.00(-3)\end{array}$ & $\begin{array}{l}9.26(-1) \\
6.34(-2) \\
1.88(-2)\end{array}$ & $\begin{array}{l}9.0(-1) j \\
6.64(-2) j \\
1.40(-2) j\end{array}$ & $\begin{array}{l}5.3(-2)^{1} \\
1.6(-2)^{1}\end{array}$ \\
\hline $\begin{array}{r}2 p^{3} 4 p-2 p^{3} 4 d \\
5 d \\
6 d \\
7 d \\
8 d \\
9 d \\
10 d\end{array}$ & $\begin{array}{l}1.11(0) \\
1.23(-1) \\
3.78(-2) \\
1.69(-2) \\
9.15(-3) \\
5.56(-3) \\
3.67(-3)\end{array}$ & $1.18(0)$ & $\begin{array}{l}1.12(0) \\
1.20(-1) \\
3.64(-2) \\
1.61(-2) \\
8.71(-3) \\
5.30(-3) \\
3.50(-3)\end{array}$ & $\begin{array}{l}1.13(0) \\
1.19(-1)\end{array}$ & & \\
\hline $\begin{array}{r}2 p^{3} 5 p-2 p^{3} 5 d \\
6 d \\
7 d \\
8 d \\
9 d \\
10 d\end{array}$ & $\begin{array}{l}1.28(0) \\
1.59(-1) \\
5.21(-2) \\
2.42(-2) \\
1.34(-2) \\
8.37(-3)\end{array}$ & & $\begin{array}{l}1.30(0) \\
1.56(-1) \\
5.06(-2) \\
2.34(-2) \\
1.30(-2) \\
8.06(-3)\end{array}$ & & & \\
\hline $\begin{array}{r}2 p^{3} 6 p-2 p^{3} 6 d \\
7 d \\
8 d \\
9 d \\
10 d\end{array}$ & $\begin{array}{l}1.46(0) \\
1.90(-1) \\
6.43(-2) \\
3.05(-2) \\
1.72(-2)\end{array}$ & & $\begin{array}{l}1.48(0) \\
1.88(-1) \\
6.28(-2) \\
2.97(-2) \\
1.68(-2)\end{array}$ & & & \\
\hline $\begin{array}{r}2 \mathrm{p}^{3} 7 \mathrm{p}-2 \mathrm{p}^{3} 7 \mathrm{~d} \\
8 \mathrm{~d} \\
9 \mathrm{~d} \\
10 \mathrm{~d}\end{array}$ & $\begin{array}{l}1.63(0) \\
2.19(-1) \\
7.53(-2) \\
3.62(-2)\end{array}$ & & $\begin{array}{l}1.66(0) \\
2.17(-1) \\
7.39(-2) \\
3.54(-2)\end{array}$ & & & \\
\hline
\end{tabular}


Table 8. Continued.

\begin{tabular}{rlc} 
Transition & \multicolumn{1}{c}{$\mathrm{BH} 1$} & $\mathrm{BZ}$ \\
$2 \mathrm{p}^{3} 8 \mathrm{p}-2 \mathrm{p}^{3} 8 \mathrm{~d}$ & $1.80(0)$ & $1.83(0)$ \\
$9 \mathrm{~d}$ & $2.46(-1)$ & $2.44(-1)$ \\
$10 \mathrm{~d}$ & $8.56(-2)$ & $8.43(-2)$ \\
& & $2.01(0)$ \\
$2 \mathrm{p}^{3} 9 \mathrm{p}-2 \mathrm{p}^{3} 9 \mathrm{~d}$ & $1.97(0)$ & $2.70(-1)$ \\
$10 \mathrm{~d}$ & $2.72(-1)$ & $2.18(0)$ \\
$2 \mathrm{p}^{3} 10 \mathrm{p}-2 \mathrm{p}^{3} 10 \mathrm{~d}$ & $2.14(0)$ &
\end{tabular}

Notes.

BHI = Bell and Hibbert (1990) with OPACITY codes (length values only).

BH2 = Bell and Hibbert (1990) with CIV3 code (length values only).

BZ = Butler and Zeippen (1990) with OPACITY codes (length values only).

PS = Pradhan and Saraph (1977) with UCL codes.

See text for details.

Other calculations.

$\mathrm{a}=$ Froese Fischer (1987).

$\mathrm{b}=$ Ganas (1980).

$i=$ Zeippen et a1. (1977).

Experiment.

c = Smith et al. (1971).

$\mathrm{d}=$ Lin et a1. (1972).

$\mathrm{e}=$ Clyne and Piper (1976).

$\mathbf{f}=$ Reader et al. (1980).

$\mathrm{g}=$ Jenkins (1985).

$\mathrm{h}=$ Doering et a1. (1985).

$j=$ Wiese et al. (1966).

$k=$ Kroll et a1. (1985).

1 = Bromander et al. (1978).

$\mathbf{m}=$ Bischel et a1. (1981).

$\mathrm{n}=$ Kernahan and Simpson (1982). 